\title{
Molecular imprinted nanoelectrodes for ultra sensitive detection of ovarian cancer marker
}

\author{
Subramanian Viswanathan, Chinnakkaruppanan Rani, Susana Ribeiro, Cristina Delerue-Matos
}

\begin{abstract}
The relentless discovery of cancer biomarkers demands improved methods for their detection. In this work, we developed protein imprinted polymer on three-dimensional gold nanoelectrode ensemble (GNEE) to detect epithelial ovarian cancer antigen-125 (CA 125), a protein biomarker associated with ovarian cancer. CA 125 is the standard tumor marker used to follow women during or after treatment for epithelial ovarian cancer. The template protein CA 125 was initially incorporated into the thin-film coatingand, upon extraction of protein from the accessible surfaces on the thin film, imprints for CA 125 were formed. The fabrication and analysis of the CA 125 imprinted GNEE was done by using cyclic voltam- metry (CV), differential pulse voltammetry (DPV) and electrochemical impedance spectroscopy (EIS) techniques. The surfaces of the very thin, protein imprinted sites on GNEE are utilized for immunospe- cific capture of CA 125 molecules, and the mass of bound on the electrode surface can be detected as a reduction in the faradic current from the redox marker. Under optimal conditions, the developed sensor showed good increments at the studied concentration range of $0.5-400 \mathrm{U} \mathrm{mL}^{-1}$. The lowest detection limit was found to be $0.5 \mathrm{U} \mathrm{mL}^{-1}$. Spiked human blood serum and unknown real serum samples were analyzed. The presence of non-specific proteins in the serum did not significantly affect the sensitivity of our assay. Molecular imprinting using synthetic polymers and nanomaterials provides an alternative approach to the trace detection of biomarker proteins.
\end{abstract}

Keywords:

Gold nanoelectrode, Ovarian cancer, Biomarker, CA 125, Molecular imprinted biosensor

\section{Introduction}

Ovarian cancer is one of the most frequent cancers among women, and it leads to more deaths than any other type of female reproductive cancer. Ovarian cancer is a cancer that forms in the tissues of the ovary. Most ovarian cancers are either ovarian epithelial carcinomas or malignant germ cell tumors. Ovarian cancer symptoms are often vague. The majority of ovarian cancers are detected at a late stage resulting in high mortality rates. Thus, it is essential to develop inexpensive and simple methods for early diagnosis (Geurts et al., 2011; Zhu et al., 2011). Over a decade of omics investigations have identified many potential biomarkers for ovarian cancer but only a few are currently used in the clinic. Early Detection Research Network (EDRN), a program run by the National Cancer Institute $(\mathrm{NCI})$, released its evaluation of the performance of 35 previously reported markers of ovarian cancer (Cramer et al., 2011). They also stated that many of these markers claimed to be better than CA 125 (cancer antigen 125), one of only two markers approved for monitoring ovarian cancer. A cancer antigen 125
(CA 125) is a protein found on the surface of many ovarian cancer cells (Peng et al., 2011). When the researchers measured the markers in 180 diseases, and 660 control specimens obtained as part of NCI's Prostate, Lung, Colorectal \& Ovarian Cancer Screening Trial, none of the new markers was better than CA 125, after all (Arnaud, 2011). Normal blood levels are usually less than $35 \mathrm{U} \mathrm{mL}^{-1}$ (units per milliliter). More than $90 \%$ of women have high levels of CA 125 when the cancer is advanced. CA 125 levels are also elevated in about half of women whose cancer has not spread outside of the ovary. If the CA 125 level is increased at the time of diagnosis, changes in the CA 125 level can be used during treatment to get an idea of how well it is working. This is why CA 125 has been studied as a screening test.

In general, a number of high-performing protein detection protocols are under development (Wang and Yau, 2011), and many of the most specific and sensitive use micro- and nanomaterials in their sensing schemes (Perfezou et al., 2012). Gold nanomaterials (Ho et al., 2010; Wei et al., 2011), carbon nanotubes (Viswanathan et al., 2009; Yu et al., 2006), barcoded nanoparticles (Lin et al., 2011; Yu et al., 2006), nanowire transistors (Ionescu, 2010), enzyme-labeled beads (Mani et al., 2009; Rissin et al., 2010), micro-nanoarrays (Das and Kelley, 2011) and microfluidic immunoarrays (Chen et al., 2009; Chikkaveeraiah et al., 2011) used 


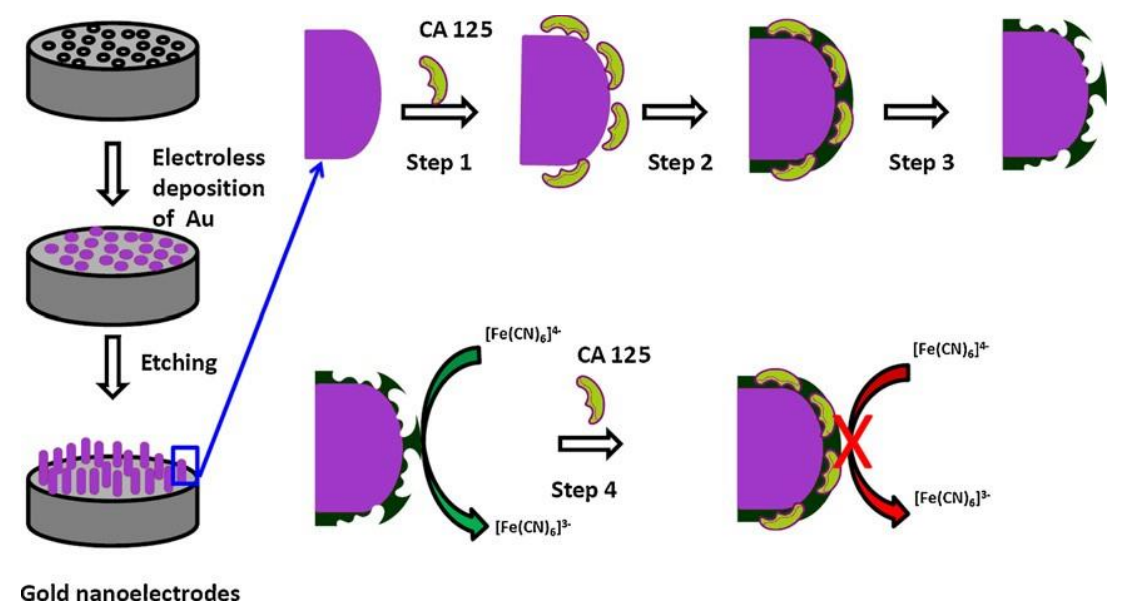

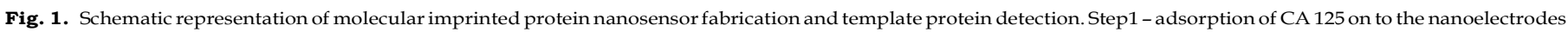
surface; Step 2 - electrochemical polymerization of phenol; Step 3 - template protein removal; Step 4 - CA 125 binding and signal generation.

with electrochemical transduction all reveal eminent capability for the development of cancer biomarker detection. Current analytical methods are in general cumbersome or time-consuming; they usually assay a single protein; are often costly; and, in the case of antibody-based assays, there are occasional concerns stemming from the cross-reactivity of the detecting antibody. Still challenges remain, however, pertaining to the development of simple analysis systems that are cost-effective and robust enough for clinical use.

Molecular imprinting (MI) technology provides considerable potential as a cost-effective alternative to the use of biomolecule based recognition in a variety of sensor applications (Cai et al., 2010). Molecular imprinting is a technique that creates synthetic materials containing specific receptor sites having a high affinity for a target molecule. Molecular imprinted polymers (MIPs) are crosslinked polymers, which are synthesized in the presence of template molecules. Three-dimensional cavities are created within a polymeric matrix that is complementary to the size, shape, and functional group orientation of the target molecule. The imprinted polymer cavity allows the target molecules to occupy the cavity space, while the functional group orientation within the cavity will preferentially bind in specific locations to only the target molecule. Deposition of MIPs onto the surface of nanostructures improves sensitivity for the recognition of a range of organic compounds. Whitcombe et al. (2011) extensively reviewed many methods used for imprinting recognition for protein targets in polymers and their incorporation with a number of transducer platforms with the aim of identifying the most promising approaches for the preparation of MIP-based protein sensors Protein imprinted polymers (Whitcombe et al., 2011). Recently Wang et al. developed a surface molecular imprinting using self-assembled monolayers to design sensing elements for the detection of CEA cancer biomarker (Wang et al., 2010).

Electrodics at microscopic and nanoscopic dimensions constitutes one of the frontiers in electrochemical science. The micro or nanoelectrode ensembles have been used for the development of electrochemical sensors. They offer numerous benefits over the conventional macroelectrodes such as enhanced mass transport, lowered influence of the solution resistance, low detection limit, and better signal-to-noise ratio $(\mathrm{S} / \mathrm{N})$. In principle, the electroanalytical detection limits at a nanoelectrode ensemble will be much lower than that at an analogous macro sized electrode because the ratio of faradic to the capacitive current is significantly high at ensemble electrodes. The colloidal chemical approach has been conveniently used for the development of ultramicroelectrodesand nanoelectrode ensembles (Kumar Jena and Retna Raj, 2008).
In the present investigation, considering the importance of the detection of CA 125 biomarker in blood serum, we have explored the possible utilization of the molecular imprinted gold nanoelectrodeensembles (MIPGNEE) for the determination of CA 125. Fig. 1 depicts the outline of an analytical technique that we developed for the determination of CA 125.

\section{Experimental}

\subsection{Reagents}

CA 125 antigen was obtained from Abcam, UK. Human blood serum is collected from healthy and infected female volunteers. All other reagents human serum albumin (HSA), potassium ferricyanide $\left(\mathrm{K}_{3}\left[\mathrm{Fe}(\mathrm{CN})_{6}\right]\right)$, potassium ferrocyanide trihydrade $\left(\mathrm{K}_{4}\left[\mathrm{Fe}(\mathrm{CN})_{6}\right]\right)$, phenol, and acetic acid, sodium dodecyl sulfate and other chemicals and solvents were purchased from Sigma-Aldrich.

\subsection{Preparation of the gold nanoelectrode ensembles}

Gold nanoelectrode ensembles were prepared by using electroless deposition of the gold within the $50 \mathrm{~nm}$ pores of polycarbonate particle track-etched membranes. A simple controlled solvent etching procedure based on the solubility of polycarbonate membranes in solvent mixtures is adopted for the fabrication of the 3D GNEE (Krishnamoorthy and Zoski, 2005). Please refer Supporting information for detailed experimental method. SEM images were obtained using a scanning electron microscope (JEOL, Model FEI Quanta 400FEGESEM/EDAX PEGASUS X4M).

\subsection{Electrochemical measurements}

All electrochemical experiments were carried out using an Autolab PGSTAT 12, potentiostat/galvanostat with a three-electrode electrochemical system was configured by connecting gold nanoelectrode ensamples, an $\mathrm{Ag} / \mathrm{AgCl}$ reference electrode and a platinum wire as auxiliary electrode. A $2 \mathrm{~mm}$ diameter hole was punched in a piece of Teflon ${ }^{\circledR}$ adhesive tape with a thickness of 0.08 and then pasted onto the membrane so that the exposed copper tape was also sealed on both sides to prevent exposure to the electrolytesolution. Electrochemical impedancespectroscopy(EIS) was used to monitor impedance changes of the electrode surface and its interface to the electrolyte containing $0.5 \mathrm{mMK}_{3}\left[\mathrm{Fe}(\mathrm{CN})_{6}\right]$, $1.5 \mathrm{mM} \mathrm{K}_{4}\left[\mathrm{Fe}(\mathrm{CN})_{6}\right]$, in $0.1 \mathrm{M}$ phosphate buffer solution (PBS) at $\mathrm{pH}$ 7.4. An a.c. sine-wave voltage was applied to the working electrode with a superimposed d.c. voltage at $0.200 \mathrm{mV}$. The AC voltage 
amplitude used was $10 \mathrm{mV}$, and the equilibrium time was $10 \mathrm{~min}$. Thefrequency varied from $1 \mathrm{~Hz}$ to $1 \mathrm{MHz}$. Theimpedance data were then represented in the form of Nyquist plots, which were fitted to anequivalentcircuit by theanalysisfunction in Nova(Autolab) software. Differential pulsevoltammetry (DPV) wasconducted in $0.1 \mathrm{M}$ PBS (pH 7.4) containing $0.5 \mathrm{mMK}_{3}\left[\mathrm{Fe}(\mathrm{CN})_{6}\right], 0.5 \mathrm{mMK}_{4}\left[\mathrm{Fe}(\mathrm{CN})_{6}\right]$ and $0.1 \mathrm{M} \mathrm{KCl}$. The initial and final potentials versus the reference electrode were 0.0 and $0.5 \mathrm{~V}$, respectively. The modulation amplitude was $50 \mathrm{mV}$, and the modulation time $0.05 \mathrm{~s}$; the step potential was $2 \mathrm{mV}$ and the interval time $0.1 \mathrm{~s}$.

\subsection{Electropolymerization of phenol on nanoelectrode surface}

Polyphenol (PP) film was electropolymerized on the exposed nanoelectrode surface by cyclic voltammetry $(\mathrm{CV})$ in phosphate buffered saline (PBS) containing $2 \mathrm{mM}$ phenol ( $\mathrm{pH} 7.4$ ). Totheworking electrode a 'ramping' voltage was applied at a scanning rate of $50 \mathrm{mV} \mathrm{s}^{-1}$ between 0.0 and $0.9 \mathrm{~V}$ versus $(\mathrm{Ag} / \mathrm{AgCl})$ for 10 cycles. To entrap template proteins in the PP coating, GNEE was incubated with $50 \mu \mathrm{L}$ of $400 \mathrm{U} \mathrm{mL}^{-1} \mathrm{CA} 125 \mathrm{in} \mathrm{pH} 7.4$ at $4{ }^{\circ} \mathrm{C}$ for $15 \mathrm{~min}$ followed by application of 10 cycles of voltage scanning, as described above. CA 125 moleculeswereadsorbed on GNEE by physisorption due to electrostatic and hydrophobic interactions between the CA 125 and the surface of GNEE.

\subsection{Protein imprinted electrode preparation}

For protein imprinted electrode preparation, the nanoelectrode surface with protein-entrapped PP coating was rinsed and incubated overnight in deionized water at room temperature. In some instances, a developing buffer containing $1 \%$ acetic acid and $3 \%$ sodium dodecyl sulfate was used, which resulted in higher protein extraction efficiency (Cai et al., 2010). After protein entrapment and removal, the sample was evaluated by EIS. Before measuring template protein rebinding, DPV was repetitively performed in a template-protein-free buffer solution until the current stabilized. Nanosensor responses were then measured by DPV or EIS following incubation for $30 \mathrm{~min}$ at room temperature with the CA 125 at various concentrations.

\subsection{Assay procedure}

TheMIPGNEE wasincubated for 30 minat $25 \pm 3^{\circ} \mathrm{C}$ with $20 \mu \mathrm{L}$ of the CA 125 standard or spiked or real samples followed by washing with PBS (0.05 M, pH 7.0). The DPV was recorded as described previously. The electrode was regenerated by extraction of bound CA 125 protein from imprinted binding cavities was done by washing with deionized water at room temperature.

\subsection{Serum collection}

Blood serum samples were prepared by collecting venous blood samples from female volunteers in BD Vacutainer ${ }^{\circledR}$ SST $^{\mathrm{TM}}$ GEL Tubes (Becton Dickinson, India). The SST tubes were allowed to clot, and the tubes were centrifuged at $1300 \times g$. The separated serum was decanted for use. The same procedures were followed for serum samples from healthy personals.

\subsection{Safety notes}

Clinical serum samples are biohazardous should be handled with care. Carcinogenic organic solvents and toxic chemicals such as phenol were used in this study and should be handled with care.

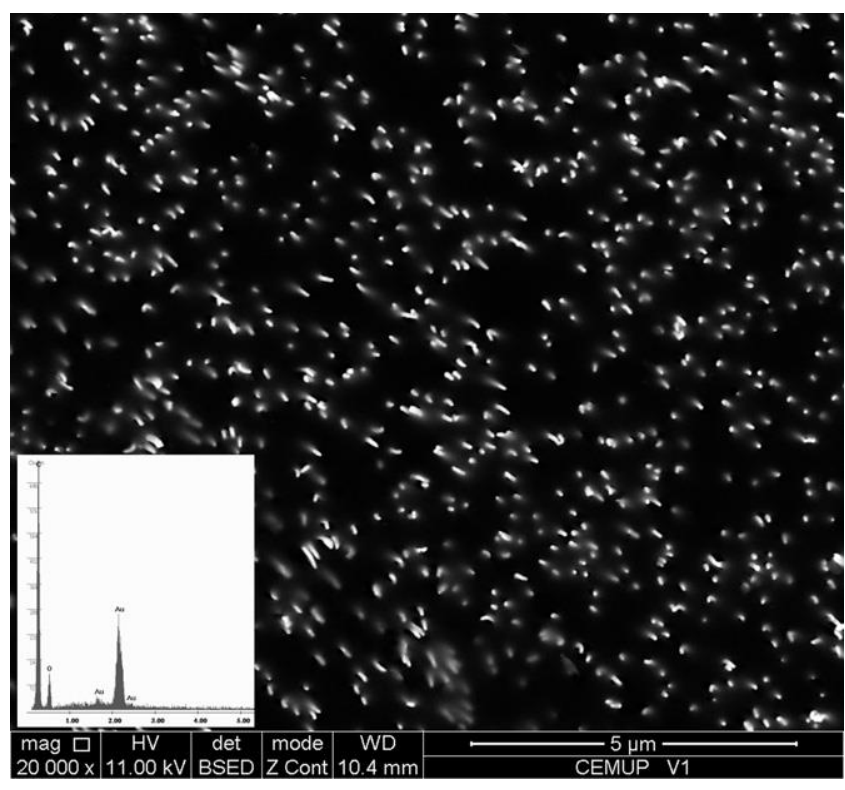

Fig. 2. Scanning electron microscopy image of a gold nanoelectrode ensembles.

\section{Results and discussions}

\subsection{Electrode fabrication}

Scanning Electron Microscopy (SEM) surface image of the membrane shows gold nanowires with an average diameter of $50 \mathrm{~nm}$ and a length of $180 \pm 20 \mathrm{~nm}$ was shown in Fig. 2. It indicates the absence of voids on the surface, indicating that this method efficiently produces 3D GNEEs with protruding gold wires. Based on this image the nanowires density was found to be $\sim 6$ nanoelectrodes $\mu \mathrm{m}^{-2}$, which is in accordance with the declared pore density, thus confirming that each template pore was filled with gold. A good electronic conduction was established between the nanoelectrode ensembles and the copper tape when the GNEE was connected to the external circuit. The results of energy dispersive X-ray (EDX) measurements evidenced that the used procedure minimized chemical contamination from the gold deposition process during the preparation of the GNEEs.

\subsection{Protein imprinting studies}

CA 125 is a high molecular weight, non-mucinoid glycoprotein (M.W. $200 \mathrm{kDa}$ approx.) which is made up of about $25 \%$ carbohydrate. CA 125 protein imprints were made by pre-adsorbed template proteins on the nanoelectrodes to entrap within the PP coating. The template protein CA 125 was initially incorporated into the thin film coating and, upon extraction of protein creates the accessible surfaces on the thin film, sensor electro chemical impedance was found to be greatly reduced due to electrical leakage through the surface imprinted sites in the PP film on GNEE. Subsequent recognition of the template protein was detected as an increase in impedance due to the relatively lower conductivity of the protein (Cai et al., 2010). A critical component for the assembly of the sensor design comprised electropolymerizing a nonconductive polyphenol (PP) nanocoating onto the nanoelectrodes. The deposition was self-limiting and yielded a highly conformal nanocoating that is beneficial in low-noise recordings (Fig. S1). The peak current (around at $1.6 \mathrm{~V}$ ) of phenol polymerization at first cycle was significantly varied with the concentration of CA 125 used for adsorption on 

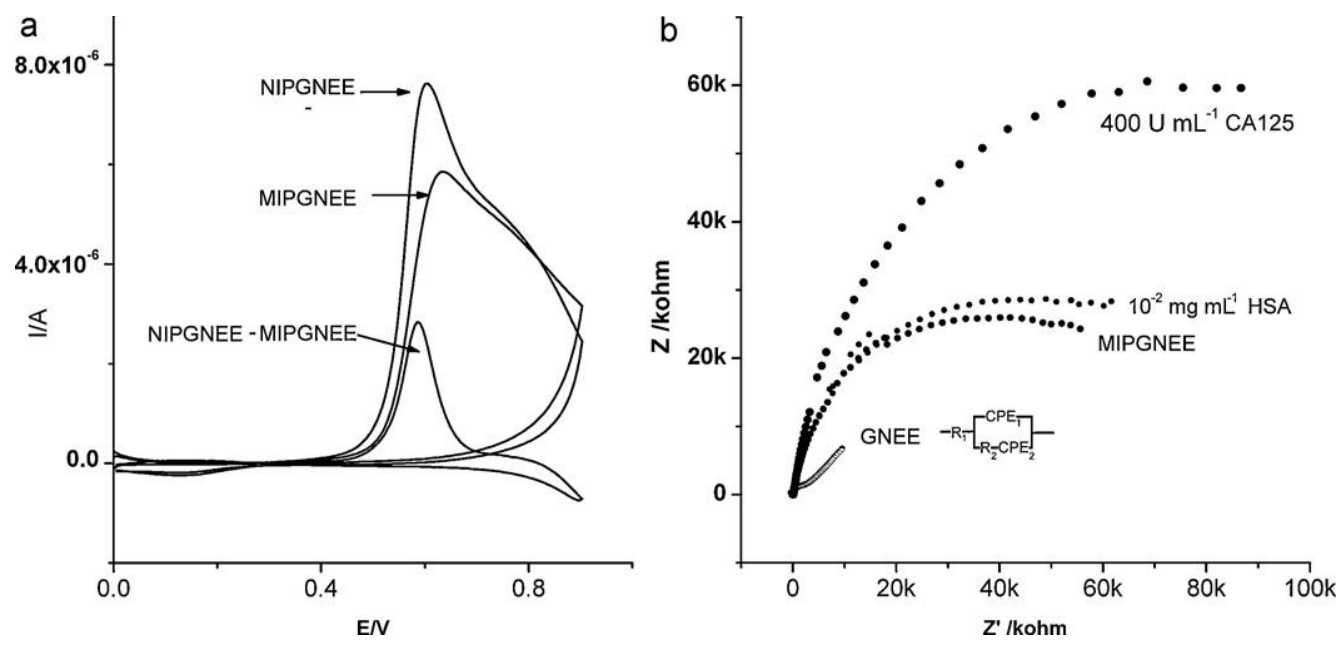

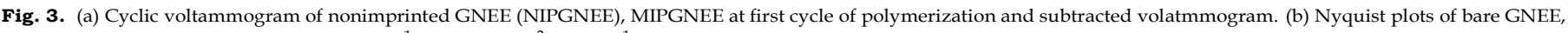
MIPGNEE incubated with CA $125400 \mathrm{U} \mathrm{mL}^{-1}$ and HSA $10^{-2} \mathrm{mg} \mathrm{mL}^{-1}$ (frequency scanned from $1 \mathrm{~Hz}$ to $1 \mathrm{MHz}$ ).

GNEE. The peak current was decreased from 50 to $300 \mathrm{U} \mathrm{mL}^{-1}$ of CA 125, with further increase in the CA 125 concentration to $300-400 \mathrm{U} \mathrm{mL}^{-1}$, the significant decrease of the charge was not observed (inset Fig. S1(a)). So, $300 \mathrm{U} \mathrm{mL}^{-1}$ was taken as optimum template protein concentration for imprint polymerization.

Estimation of the number of CA 125 imprints was calculated by difference between the integrated charge for the electrochemical polymerization at bare GNEE and CA 125 absorbed GNEE. For these experiments, the GNEE were coated with only PP or CA 125 entrapped PP. First CV scan cycle of PP electropolymerization on GNEE and CA 125-GNEE is shown in Fig. 3a. A significant current loss was observed for the CA 125 adsorbed electrode. PP was not deposited in CA 125 adsorbed sites, we converted the charge difference to the volume of PP and then the amount of CA 125 imprints according to the dimensions of the CA 125 molecule. According to the voltammogram, the charge difference of imprint was $5.72 \mu \mathrm{C}$, while the charge due to without imprint protein and with imprint was $41.13 \mu \mathrm{C}$ and $37.99 \mu \mathrm{C}$ respectively. Scan cycle number 10 was considered as residual background current and was subtracted. Therefore, the imprints contributed charge was $5.72 \mu \mathrm{C}$ which is equivalent to the amount of protein adsorbed or imprintsites. Thearea of imprint wascalculated using the following equation.

The volume of $\mathrm{PP}\left(V_{\mathrm{PP}}\right)$ was calculated from the following equation (Cai et al., 2010):

$V_{\mathrm{PP}}=\frac{m Q_{\mathrm{GNEE}}}{k F \sigma}$

$m$ is the molecular weight of phenol, $Q_{\mathrm{GNEE}}$ is the total charge difference generated during the deposition, $F$ is the Faradic constant and $c r$ is the density of phenol and equals to $1 \mathrm{mg} \mathrm{mm}^{-3}, k$ is the correction coefficient (Cai et al., 2010).

In these experiments, the volume of $\mathrm{PP}\left(V_{\mathrm{PP}}\right)$ corresponds to:

$$
\begin{aligned}
V_{\mathrm{PP}} & =\frac{\left(94.1 \times 5.72 \times 10^{-6}\right)}{\left(9.1 \times 6.02 \times 10^{23} \times 1.6 \times 10^{-19} \times 10^{-3}\right)} \\
& =6.14 \times 10^{-7} \mathrm{~mm}^{3}
\end{aligned}
$$

CA 125 is a glycoprotein with a molecular weight of $\sim 200 \mathrm{kDa}$. Hence, assuming the size of CA 125 is $\sim 10 \mathrm{~nm}$ diameter and made the following calculation to measure approximate number of imprints on the sensor.
Therefore, the total amount of imprints $\left(N_{\mathrm{MI}}\right)$ was: $N_{\mathrm{MI}}=$ $V_{\mathrm{PP}} / V_{\mathrm{CA} 125}=1.17 \times 10^{9} . \quad$ Nanoelectrodes density $N_{\mathrm{GNEE}}=$ 6 nanoelectrode $\mu \mathrm{m}^{-2}$. Therefore the number of nanoelectrodes on working electrode $(2 \mathrm{~mm}$ diameter $)=1.88 \times 10^{7}$.

So the number of protein imprints on each nanoelectrode $=N_{\mathrm{MI}} / N_{\mathrm{GNEE}}=62.3$.

The detection of CA 125 binding to its imprinted site was evaluated using EIS. Nyquist plots show the impedance spectroscopy of the MIPGNEE sensor at different stages of development of MIPGNEE (Fig. 3b). The bare GNEE electrode exhibited almost the straight line in Nyquist plots, which is characteristic for a diffusion limiting step of electrochemical process (Fig. 3b). However, MIPGNEE showed a semicircle plot at higher frequencies. It indicated that the electrode redox processes mass transfer was the electrontransfer limited. The electron transfer kinetics on the electrode surface originates from the formation of ion transfer channels caused by protein imprinted sites. MIPGNEE yielded higher resistance for the interfacial electron transfer upon incubation with $400 \mathrm{UmL}^{-1}$ of CA 125 . However, $10^{-2} \mathrm{mg} \mathrm{mL}^{-1}$ of HSA did notexert a significant impedance change. These EIS measurements revealed that the MIPGNEE had the good selectivity and sensitivity for CA 125 .

\subsection{Analytical calibration}

The analytical calibration for CA 125 was conducted to determine the sensitivity of the MIPGNEE sensor to CA 125, and the MIPGNEE were tested with different concentrations of CA 125 in PBS $\mathrm{pH}$ 7.4. The calibration curve for the voltammetric detection of CA 125 was carried out by recording, for each concentration, the response of a MIPGNEE at optimum experimental conditions (Fig. 4). Each point of the calibration graph corresponds to the mean value obtained from 5 independent measurements. The limit of detection (LOD) was defined as the lowest concentration of biomarker producing a peak current 3 times higher than the standard deviation of the peak current in the absence of CA 125 under identicalconditions. Asigmoidalcurvefor thecurrentvariationwas observed over the range $1-400 \mathrm{U} \mathrm{mL}^{-1}$ with LOD $0.5 \mathrm{U} \mathrm{mL}^{-1}$. Replicated analysis for CA $125\left(10 \mathrm{U} \mathrm{mL}^{-1}\right)$ led to a standard deviation 3.1 for 5 independent analyses. It indicated that the imprinted sensor response and fabrication procedure were reproducible. MIPGNEE were regenerated up to 20 cycles without significant loss its efficiency (Fig. S2). Theinterference protein response on the MIPGNEE was shown in inset Fig. 4c. It clearly indicates the absence of significant interferes on CA 125 determination. 
Table 1

Determination of CA 125 present in spiked and real human serum samples.

\begin{tabular}{|c|c|c|c|c|c|}
\hline \multirow[t]{2}{*}{ Source } & \multicolumn{3}{|l|}{ Proposed sensor } & \multicolumn{2}{|c|}{ Reference method ELISA } \\
\hline & Added $\left(\mathrm{U} \mathrm{mL}^{-1}\right)$ & Found $\left(\mathrm{U} \mathrm{mL}^{-1}\right)$ & Std. dev. $(n=5)$ & Found $\left(\mathrm{U} \mathrm{mL}^{-1}\right)$ & Std. dev. $(n=5)$ \\
\hline \multirow{3}{*}{$\begin{array}{l}\text { Spiked blood } \\
\text { serum samples }\end{array}$} & 10 & 9 & 2.5 & 12 & 3.8 \\
\hline & 50 & 45 & 6.4 & 41 & 7.5 \\
\hline & 100 & 96 & 8.4 & 98 & 9.3 \\
\hline Infected patient & - & 85 & 7.9 & 76 & 8.3 \\
\hline Healthy person & - & 17 & 4.4 & 15 & 3.6 \\
\hline
\end{tabular}

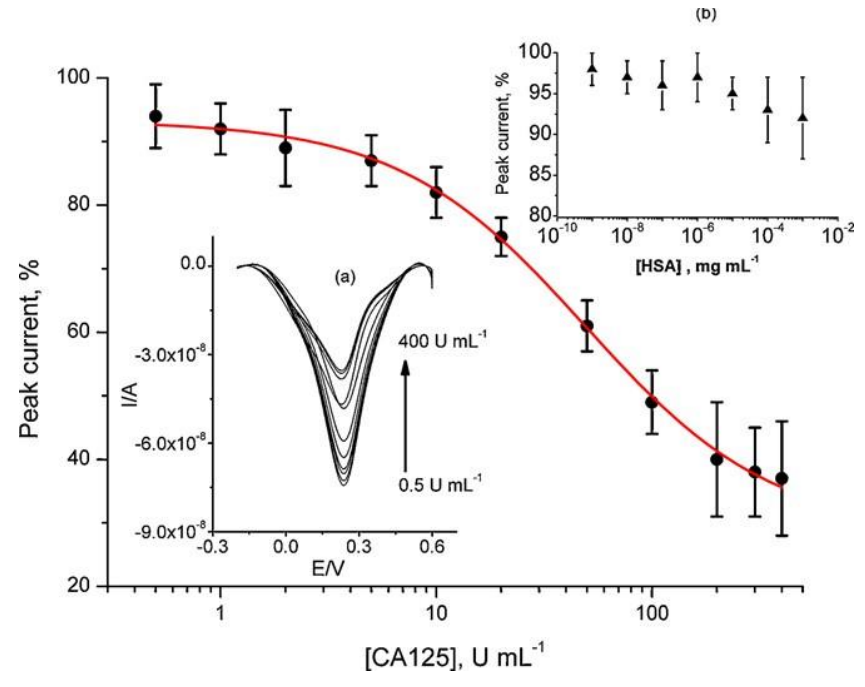

Fig. 4. CA 125 concentration-dependent peak current response represented as the percentage of peak current (\%) versus concentration $\left(\mathrm{U} \mathrm{mL}^{-1}\right)$ on semi log plot. Inset (a), DPV current responses to CA 125. Inset (b), DPV current responses to different HSA concentrations.

\subsection{CA 125 in human serum samples}

Direct determination of serum CA 125 level is very important in the early detection of ovarian cancer. Human serum samples were spiked with known amount CA 125 and analyzed for method validation. The accuracy of the CA 125 determination was examined by comparison of the results obtained by this method with those from the ELISA CA 125 analysis kit (BioCheck, Inc., CA). The CA 125 contents in unknown real serum samples were also quantified with both techniques. All results were given in Table 1. These results of both methods were thus in good agreement. Experimental results revealed that the proposed imprinted sensor showed better sensitivity, recovery with reproducibility.

\section{Conclusions}

In conclusion, the performance and clinical utility of CA 125 molecular imprinted nanoelectrodes sensor were analyzed. The integration of the molecular imprinting technology and nanotechnology meets the demand of facilitating the electrochemical sensor detection levels. The gold nanoelectrodes ensembles improve the performance of the electrochemical reaction of substrate and increase the sensitivity of the CA 125 detection. This developed sensor showed good reproducibility in human serum samples. Serum testing using proposed biosensor is simple, making it an attractive, effective alternative to conventional ELISA testing, and the possibility of developing home testing kits would further facilitate it as a diagnostic aid, enabling patients to monitor their own health at home and is important for those who live far from their treatment centers. Summarily, the proposed method had potential to be further developed for practical clinic cancer diagnosis.

\section{Acknowledgements}

We thank Dr. R. Vengatesan, (Dental surgeon) for his much appreciated support and care during sample collection. We also thank the volunteers who participated in this study. The authors acknowledge the financial support from Fundação para a Ciência e Tecnologia, Portugal (Project reference no. PTDC/SAUENB/114786/2009).

\section{Appendix A. Supplementary data}

Supplementary data associated with this articlecan be found, in the online version, at doi:10.1016/j.bios.2011.12.049.

\section{References}

Arnaud, C.H., 2011. Chem. Eng. News 89 (30), 40-43.

Cai, D., Ren, L., Zhao, H., Xu, C., Zhang, L., Yu, Y., Wang, H., Lan, Y., Roberts, M.F., Chuang, J.H., Naughton, M.J., Ren, Z., Chiles, T.C., 2010. Nat. Nanotechnol. 5 (8), 597-601.

Chen, H., Jiang, C., Yu, C., Zhang, S., Liu, B., Kong, J., 2009. Biosens. Bioelectron. 24 (12), 3399-3411.

Chikkaveeraiah, B.V., Mani, V., Patel, V., Gutkind, J.S., Rusling, J.F., 2011. Biosens. Bioelectron. $26(11), 4477-4483$.

Cramer, D.W., Bast Jr., R.C., Berg, C.D., Diamandis, E.P., Godwin, A.K., Hartge, P., Lokshin, A.E., Lu, K.H., McIntosh, M.W., Mor, G., Patriotis, C., Pinsky, P.F., Thornquist, M.D., Scholler, N., Skates, S.J., Sluss, P.M., Srivastava, S., Ward, D.C., Zhang, Z., Zhu, C.S., Urban, N., 2011. Cancer Prev. Res. 4 (3), 365-374.

Das, J., Kelley, S.O., 2011. Anal. Chem. 83 (4), 1167-1172.

Geurts, S.M.E., de Vegt, F., van Altena, A.M., van Dijck, J.A.A.M., Tjan-Heijnen, V.C.G., Verbeek, A.L.M., Massuger, L.F.A.G., 2011. Int. J. Gynecol. Cancer 21 (5), $837-845$.

Ho, J.-a.A., Chang, H.-C., Shih, N.-Y., Wu, L.-C., Chang, Y.-F., Chen, C.-C., Chou, C., 2010. Anal. Chem. 82 (14), 5944-5950.

Ionescu, A.M., 2010. Nat. Nanotechnol. 5 (3), 178-179.

Krishnamoorthy, K., Zoski, C.G., 2005. Anal. Chem. 77 (15), 5068-5071.

Kumar Jena, B., Retna Raj, C., 2008. Anal. Chem. 80 (13), 4836-4844.

Lin, J., Wei, Z., Mao, C., 2011. Biosens. Bioelectron. 29 (1), 40-45.

Mani, V., Chikkaveeraiah, B.V., Patel, V., Gutkind, J.S., Rusling, J.F., 2009. ACS Nano 3 (3), 585-594.

Peng, N.-J., Liou, W.-S., Liu, R.-S., Hu, C., Tsay, D.-G., Liu, C.-B., 2011. Cancer Biother. Radiopharm. 26 (2), 175-181.

Perfezou, M., Turner, A., Merkoci, A., 2012. Chem. Soc. Rev., doi:10.1039/C1CS15134G.

Rissin, D.M., Kan, C.W., Campbell, T.G., Howes, S.C., Fournier, D.R., Song, L., Piech, T., Patel, P.P., Chang, L., Rivnak, A.J., Ferrell, E.P., Randall, J.D., Provuncher, G.K., Walt, D.R., Duffy, D.C., 2010. Nat. Biotechnol. 28 (6), 595-599.

Viswanathan, S., Rani, C., Anand, A.V., Ho, J.-a.A., 2009. Biosens. Bioelectron. 24 (7), 1984-1989.

Wang, J., Yau, S.-T., 2011. Biosens. Bioelectron. 29 (1), 210-214.

Wang, Y., Zhang, Z., Jain, V., Yi, J., Mueller, S., Sokolov, J., Liu, Z., Levon, K., Rigas, B., Rafailovich, M.H., 2010. Sens. Actuators B-Chem. 146 (1), 381-387.

Wei, Q., Zhao, Y., Xu, C., Wu, D., Cai, Y., He, J., Li, H., Du, B., Yang, M., 2011. Biosens. Bioelectron. 26(8), 3714-3718.

Whitcombe, M.J., Chianella, I., Larcombe, L., Piletsky, S.A., Noble, J., Porter, R., Horgan, A., 2011. Chem. Soc. Rev. 40 (3), 1547-1571.

Yu, X., Munge, B., Patel, V., Jensen, G., Bhirde, A., Gong, J.D., Kim, S.N., Gillespie, J., Gutkind, J.S., Papadimitrakopoulos, F., Rusling, J.F., 2006. J. Am. Chem. Soc. 128 (34), 11199-11205.

Zhu, C.S., Pinsky, P.F., Cramer, D.W., Ransohoff, D.F., Hartge, P., Pfeiffer, R.M., Urban, N., Mor, G., Bast Jr., R.C., Moore, L.E., Lokshin, A.E., McIntosh, M.W., Skates, S.J., Vitonis, A., Zhang, Z., Ward, D.C., Symanowski, J.T., Lomakin, A., Fung, E.T., Sluss, P.M., Scholler, N., Lu, K.H., Marrangoni, A.M., Patriotis, C., Srivastava, S., Buys, S.S., Berg, C.D., Team, P.P., 2011. Cancer Prev. Res. 4 (3), 375-383. 